\title{
基于士官院校电工技术课程的研究与思考
}

\author{
黄艳艳 侯慧娜
}

空军工程大学航空机务士官学校

DOI:10.32629/mef.v1i2.30

[摘 要] 电工技术是士官高等职业技术教育各专业任职基础的主千课程, 也是一门抽象难懂的课程,对学员后续的学习有着 重要的作用。本文针对电工技术在教学中出现的问题, 通过大量的调查研究发现想要提高士官学员学习本门课的兴趣, 提高实 践能力,教员应该改变原有的教学方法,整合教学内容,优化考核模式,提高自身素质等方面入手。

[关键词]士官教育; 电工技术; 课程

“电工技术” 是士官高等职业技术教育各专业任职基础 的主干课程。主要研究电路的基本概念、基本理论和基本分 析方法。本课程对培养学员的电路识别、连接、分析和计算 能力, 养成严谨的操作习惯具有重要意义, 对实现各专业人才 培养目标具有重要支撑作用。通过对往届学员的调查发现学 员对电工知识的掌握并不扎实, 在后续专业课中遇到相关的 内容仍是不知或知之甚少, 对仪器仪表的使用不够熟练。对较 为复杂的电路图或电路故障排除仍感到无措。针对种种问题, 笔者通过大量的调查发现存在这些问题的原因, 并找出解决 的办法。

\section{1 《电工技术》教学中的问题}

1.1 理论与实践分离

《电工技术》是一门实践性很强的课程, 但在实际的教学 过程中仍采用传统的 “先理论, 后实践” 的教学模式, 即先在 多媒体教室进行理论讲授, 后到实验室进行实验。例如在讲电 阻元件时, 往往是两个学时讲完电阻的概念、电阻的分类以及 电阻的识别等, 然后再有两个学时进行电阻的连接及测量实 验。由于实验室及课时安排等条件的限制, 在理论课结束之后 不能立即实验。这样的不足之处是: 一、上理论课时由于不 能对着实物讲解会让人觉得言之无物, 空洞乏味; 二、实验前 都会涉及实验原理, 而这一部分则是理论课已经讲过的内容, 这样就会造成重复讲解; 三、本门课理论学时较多, 实验学时 较少, 这样就造成了实践教学成为理论教学的补充, 无形之中 实践教学地位下降, 导致学员在学习该课程时重理论, 轻实践, 影响学员实践技能的提高。

\section{2 学员学习方法不得当}

经调查发现学员晚上学习到很晚, 有时能到夜里十一二 点, 第二天上课时难免会打瞌睡。这样长此以往就造成了恶性 循环, 上课时提不起精神, 课余休息时间又得用来学习。士官 学员文化基础薄弱, 自学能力差, 这种本末倒置的做法使得他 们学习起来很困难, 越困难越不想学, 时间久了有些学员对本 门课程就放弃了。古希腊哲学家普罗塔戈拉曾写道: “头脑不 是一个要被填满的容器, 而是一个需要被点燃的火把。” 那么 正确引导学员变被动填鸭式的学习为创造主动性学习就显得 尤为重要。

\section{3 学员文化基础参差不齐}

学员的文化基础差异太大, 给教学带来一定的难度。在 各个班级中都会发现, 文化程度高的有本科、大专学历的, 文化程度低的初中还没有毕业。本科、大专学历的学员也有 一部分是文科生, 他们在高二高三就没有学过物理, 数学知 识学得也较浅, 自然就学不好以《数学》、《物理》为基础的 《电工技术》。例如在正弦交流电路中对相量进行计算时, 需要学员具备 “复数” 知识基础, 而很大一部分的学员在中 学对复数内容就没有接触, 进入部队后也没有学习相关的内 容, 以至学员很难理解交流电路中的相量, 自然也不会用相 量来分析计算电路。

\section{4 考核方式不合理}

考试作为教学评价的重要手段, 对学员学习有着重要的 导向作用。以往的考核中课终考核成绩占 $80 \%$, 平时成绩占 $20 \%$, 其中平时成绩中包括作业、课堂提问、小结考试、实验 报告等。我们知道理论试题的考试对基础较差的学员来说是 一个难题, 这样会挫败一部分学员学习的积极性。

\section{2 改进的措施}

2.1 改变教学方法一一理实一体化

在整个教学过程中将所有的授课内容在实验室进行 (这 需将实验室重新整修)。例如在讲电路联接时, 先讲串联、并 联、混联的定义, 然后根据电路图联接成不同电路, 依据教员 要求测量电路中的电压和电流, 总结出串联电路和并联电路 的特点。这样做的优点是: 一、可将实际电路与电路图联系 起来加深对串联电路、并联电路、混联电路的认识; 二、要 反复测量电路中的电压和电流, 这就使得学员在不断的重复 中熟练掌握万用表的使用方法; 三、串联电路和并联电路的 特点是由学员测量, 教员总结出来的, 因此学员对这一重要结 论印象深刻; 四、整个教学过程中, 理论讲授和动手操作是穿 插在一起的, 这样学员就不会因为满堂灌而乏味, 也不会因为 全程实验而解怠。再比如在讲授基尔霍夫定律时, 讲完定律的 内容后, 学员可根据教员要求, 设计一个电路, 由此可将原验 证性实验变成设计性实验, 学员自己动手设计, 自己分析, 并 独立撰写实验报告。这就很好的培养了学员动手探求规律、 学习知识的意识, 对于其实践能力的提高有极大的促进作用。 


\section{2 整合教材内容}

电工技术课程内容比较多, 而课时仅 50 学时, 所以按照 “够用、实用、有用” 的原则, 选取教学内容。根据电工教 学体系可分为五个教学模块: 电路的基本知识及定律、直流 电路的分析方法、正弦交流电路、三相交流电路、安全用电。 授课时, 对定律定理及其结论不再强调详细的数学推导, 而 着重从概念出发, 说明其原理、规律和适用范围。对一般内 容应避繁从简, 对重要的内容或问题要阐述透彻, 保持理论 深度, 详略得当将完整的知识体系交给学员。例如在讲功率 因数提高时, 应阐明什么是功率因素, 功率因素低有什么危 害, 如何提高功率因素, 有哪些措施, 是否可行, 对于这些内 容要详细讲解, 而对于提高功率因素需要并联一个电容, 这 个电容的计算公式的推导则可以省略不讲。

\section{3 授课过程中联系实际}

在授课中引入实际实例, 可增加学员的学习兴趣。例如在 讲电路的基本物理量时, 可用实际家庭电路联接引入。从配电 室引出两根线到各用户, 先接入电表, 空气开关, 然后接入各 用电器。以最常用的用电器电灯为例, 灯的明灭, 灯的明亮程 度分别引出电路的基本物理量。例子源于我们日常生活, 我们 每天都会接触到, 以此为例学员更容易接受和理解。又如在讲 解戴维南定理时, 举例: 用电高峰期为什么灯泡会变暗。这不 仅复习了前面所讲的内容, 又形象的讲解戴维南定理的应用, 例子学员都比较熟悉。由此可增加学员的学习兴趣。

\section{4 优化课程考核方式}

重视学员在教学中的过程考核。过程考核就是对学员在 课程教学过程中的学习状况和阶段性学习成果进行多方面、 多形式、分阶段的考核, 既关注学员学习能力的发展过程, 也关注学员在学习过程中的成果, 是对学习过程和学习结果 全面考察的综合考核制度, 可以引导学员改善学习态度和学 习方式, 变被动式学习为主动式、探究式学习, 提高学员学习 能力、实践能力和综合素质, 促进学员全面发展。因此考核 中比值的分布是：课终考核成绩占 $60 \%$, 过程考核占 $40 \%$, 其 中过程考核包括平时成绩和实验成绩。平时成绩由作业、课 堂提问、小结考试、学员学习态度、出勤率等组成, 每一项 都有一定的比重, 每一次上课的每一次得分都有专人记录, 而且平时成绩可以通过电脑查询, 学员能够了解其不足, 改 进学习方法, 扬长避短, 提高后续内容的学习效率。同时教员
通过分析与总结, 发现学员的薄弱环节, 不断调整教学方法, 对学习较差的学员加强沟通、交流和指导, 使教学、考核与 学员学习过程有机联系, 不断提高课程的教学水平和教学质 量。实验成绩由实验考试和实验报告两部分组成。由于理论 课和实验课融合在一起, 所以实验课考试的内容比较多, 教 员可将需要考试的内容进行整理然后制成卡片, 考试时随机 抽取, 在实验过程中每一步都有一定的分值, 以此来规范学 员的操作步骤。

\section{5 提高教员人文素养}

要使听讲者保持一种高昂的、积极的、自觉的听讲精神 状态, 除了课程内容自身的新颖性、深刻性、重要性、趣味 性以外, 教员的人文修养和专业素养也非常重要。课堂上自 然的教态、文雅的谈吐、渊博的知识、生动精彩的讲解, 会 强烈的吸引学员, 达到 “亲其师, 敬其人, 信其道” 的效果。 一个妙语连珠, 别具情趣, 具有独特的个性鬼力的教员, 在丰 富的知识教学中, 不失时机的幽默一下, 既能使学员紧朋的 神经得到放松, 又使学员在开怀大笑中接受知识, 这样的教 员往往让学员铭记终生, 永难忘怀。因此, 教员加强人文知识 的积累, 提高授课技巧和学习新的授课方法并尝试应用。在 授课过程中力求做到多讲解生动的日常生活以及最新的科 研成果等。

综上所述, 想要提高士官学员电工技术专业的整体素质, 以便于能够更好地适应部队的需求, 在教学过程中应加大改 革力度, 充分利用现代信息化教学手段, 灵活多样的教学方 法来激励和引导学员积极主动全身心投入到学习当中, 锻炼 其实践能力。

\section{[参考文献]}

[1]孙化锋.《电工技术与技能》实验实训教学探索 [J]. 计算机产品与流通,2017,(11):183-184.

[2]黄冬梅,郑翅,姜秀玲, 等.电工技术及应用课程改革方 案实施[J].哈尔滨职业技术学报.2016,(1):71-73.

[3]刘晓燕, 高晓燕, 杜荣. 数字电子技术课程教学改革探 索与实践 [J].河北交通职业技术学院学报.2017,(6):23-25.

\section{作者简介:}

黄艳艳(1983--), 女, 河南淮滨人, 硕士, 讲师, 研究方向: 电 工电子技术研究。 